\title{
The association between frailty and quality of life among rural community-dwelling older adults in Kegalle district of Sri Lanka: A cross-sectional study
}

Dhammika Deepani Siriwardhana, Research Department of Primary Care and Population Health, University College London, Rowland Hill Street, London, NW3 2PF, UK and Department of Disability Studies, Faculty of Medicine, University of Kelaniya, P.O. Box 6, Thalagolla Road, Ragama, 11010, Sri Lanka (ORCD ID: 0000-0003-2313-3095)

Manuj Chrishantha Weerasinghe, Department of Community Medicine, Faculty of Medicine, University of Colombo, No. 25, Kynsey Road, Colombo 08, Sri Lanka

Greta Rait, Research Department of Primary Care and Population Health, University College London, Rowland Hill Street, London, NW3 2PF, UK (ORCD ID: 0000-0002-7216-7294)

Shaun Scholes, Research Department of Epidemiology and Public Health, University College London, 1-19 Torrington Place, London, WC1E 7HB, UK

Kate R Walters, Research Department of Primary Care and Population Health, University College London, Rowland Hill Street, London, NW3 2PF, UK (ORCD ID: 0000-0003-21732430)

Corresponding author

Dhammika Deepani Siriwardhana

Research Department of Primary Care and Population Health,

UCL Medical School (Royal Free Campus)

University College London

Rowland Hill Street

London, NW3 2PF, UK

Email: deepani.siriwardhana.15@ucl.ac.uk

Phone: +44 (0)20 78302393, +94 (0) 715276905 


\section{Abstract}

\section{Purpose}

The objective of this study was to estimate the cross-sectional association of frailty with overall and domain-specific quality of life (QoL) in rural community-dwelling older adults in Kegalle district of Sri Lanka.

\section{Methods}

A population-based cross-sectional study was conducted with 746 community-dwelling older adults aged $\geq 60$ years living in the rural areas of Kegalle district of Sri Lanka in 2016. A three-stage probability sampling design was used to recruit participants. Frailty and QoL were assessed using the Fried phenotype and Older People's Quality of Life Questionnaire respectively. Multivariable linear regression was used to estimate the association of frailty with QoL after accounting for the complex sampling design.

\section{Results}

The median (IQR) age of the sample was 68 (64: 75) years and comprised of 56.7\% women. 15.2\% (95\% CI: $12.4 \%, 18.7 \%)$ were frail and 48.5\% (95\% CI: 43.9\%, 53.2\%) were pre-frail. The unadjusted means (SE) of the total QoL score for the robust, pre-frail and frail groups were $139.2(0.64), 131.8(1.04)$ and $119.2(1.35)$ respectively. After adjusting for covariates in the final multivariable model, the estimated difference in mean QoL were lower for both frail and pre-frail groups versus robust. The estimated reduction in the total QoL score was 7.3\% for those frail and $2.1 \%$ for those pre-frail. All QoL domains apart from 'social relationships and participation', 'home and neighbourhood' and 'financial circumstances' were associated with frailty.

\section{Conclusions}

Frailty was associated with a small but significant lower quality of life in this rural Sri Lankan population, which appears largely explained by 'health' and 'independence, control 
over life and freedom' QoL domains. Interventions aiming to improve quality of life in frail older adults should consider targeting these aspects.

\section{Introduction}

Frailty is an important clinical condition of older age characterised by decreased in-built physiological reserves and dysregulation of multiple physiologic systems [1]. As a consequence, frailty has been shown to increase the risk of several adverse health outcomes such as premature mortality, loss of activities of daily living, hospitalisation, risk of falls and fractures [2]. These poor outcomes along with physical, psychological and social risk factors associated with frailty could have negative impacts on the quality of life (QoL) of older adults. Alternatively experiencing poor QoL for long periods could also lead to frailty. Maintaining a strong sense of psychological well-being in later life has been found to be protective against development of physical frailty [3]. The prevalence of frailty increases with age $[4,5]$ and the QoL of frail older adults has become an important concern with increased longevity. A systematic review and meta-analysis has demonstrated a consistent inverse association between frailty, pre-frailty and health related quality of life (HRQoL) [6]. However, these studies have been limited to high income countries such as Italy [7], Taiwan [8,9] and USA [10]. We found only one study from upper middle-income countries (Mexico) [11] and no studies were found from low income or lower-middle income countries.

The concepts of QoL and HRQoL are often used interchangeably [12]. However, QoL is a broad multidimensional construct [13] whereas HRQoL more focuses on the aspects of quality of life that are influenced by one's health status directly, excluding non-health dimensions such as home and neighbourhoods and, financial circumstances. Previous studies have investigated the association between frailty and QoL [11,14-16], frailty and HRQoL [7- 
10] and frailty and psychological well-being [3] as well as subjective well-being [17]. The latter two studies used CASP-19: a measure of QoL in early old age that included four domains; control, autonomy, pleasure, and self-realis ation [18]. Only two studies used quality of life instruments that are specifically designed to assess the QoL of older adults with a broad range of domains $[11,14]$.

It is widely accepted that the construct of QoL is strongly influenced by culture [19]. Hence, cross-cultural differences of quality of life may exist. Sri Lanka is a multi-ethnic, multicultural and multi-faith country which has a deeply rooted culture of caring for older adults predominantly shaped by Buddhist principles and values. The majority of older Sri Lankan adults are supported by their own children, relatives and neighbours [20]. However, along with the urbanisation, migration and changing family structure, these cultural norms are becoming less predominant. Furthermore Sri Lanka's non-communicable disease burden is rising along with a rapidly ageing population $[21,22]$. The prevalence of depression among older adults in Sri Lanka is reported to be higher relative to other Asian countries like Taiwan, China, Korea, Malaysia and Japan [23]. Being a lower middle-income country, Sri Lanka is under huge pressure to provide adequate health and social care services for its growing older population. Hence, these context-specific micro, meso and macro level factors could be positively or negatively contributing to the QoL of frail older adults.

Two recent studies from Sri Lanka reported moderate levels of QoL [24] and poor levels of HRQoL [25] among community-dwelling older adults. To date, no studies have examined the association between frailty and QoL in World Health Organization South-East Asia region and in low and lower middle-income countries more generally. Understanding the association between frailty and QoL will inform policy on service delivery to meet the needs of frail 
older adults in order to improve QoL. The aim of this study was to estimate the crosssectional association of frailty with overall and domain-specific quality of life after adjusting for sociodemographic and health related covariates in rural community-dwelling older adults in Kegalle district of Sri Lanka.

\section{Materials and methods}

\section{Study design, setting and participants}

This is a population-based cross sectional study with older adults aged $\geq 60$ years permanently living in the rural areas of Kegalle district of Sri Lanka. We excluded those unable to give informed consent including people with severe dual hearing and vision impairment, aphasia, severe stages of dementia, those with unstable severe mental illnesses and those who were terminally ill. The sample size was calculated using the standard formula for prevalence studies [26]. The expected prevalence of frailty in rural Sri Lanka was considered as $11 \%$ based on the results of a similar study conducted in Chennai, South India [27]. The absolute precision required on either side of the prevalence estimate was set as $3.5 \%$ and the $\mathrm{z}$ statistics for the $95 \%$ level of confidence was set as 1.96 . To account for the complex sampling design, we inflated the estimated sample size by a design effect of 2.4 [28], giving a minimum sample of 737 participants. Hence, the final sample required was estimated as 750 participants. A three stage probability sampling was used to recruit older adults representing the rural areas of the entire district, which has been described in detail elsewhere [29]. 


\section{Measurements}

\section{Assessment of frailty}

Frailty was defined using the Fried phenotype [1] comprising five components; shrinking, self-reported exhaustion, weakness, slowness and low physical activity level. Components were operationalized as follows: shrinking was defined as having a body mass index (BMI) $<18.5 \mathrm{~kg} / \mathrm{m}^{2}$. Self-reported exhaustion was assessed using two questions ("I felt that everything I did was an effort" and "I could not get going") from the Center for Epidemiological Studies-Depression scale [30]. If the answer was three or more days in the last week to either of these two questions, the respondent was considered as frail for this component. Weakness was defined as being in the lowest grip strength quintile after adjusting for BMI quartiles and sex. Slowness was evaluated by being in the slowest quintile for the time taken to walk 15 feet after adjusting for median height and sex. Low physical activity level was defined as being in the lowest quintile for weekly kilocalories expenditure adjusted for sex measured using the International Physical Activity Questionnaire (Short Form) [31]. Cut-offs for weakness and slowness components were computed based on the anthropometry of our study sample accounting for the complex sampling design. As proposed in the original study [1] participants with three or more components were considered as frail, those with one or two components were considered as pre-frail and those with none of the five components described above were considered as robust/non-frail.

\section{Assessment of quality of life}

The quality of life of participants was assessed using the Older People's Quality of Life (OPQOL)-35 questionnaire, developed to measure QoL in older adults, and validated on a community-dwelling older population in Britain [32-34]. It has 35 items and participants were asked to what extent they agree with each item, with response options on a five-point 
likert scale (from "strongly agree" to "strongly disagree") coded from 1 to 5 . The OPQOL-35 questionnaire has eight sub scales; life overall, health, social relationships and participation, independence, control over life and freedom, home and neighbourhood, psychological and emotional well-being, financial circumstances, leisure activities and religion. After reverse coding for positive items, the total QoL score ranges from 35 (worst possible) to 175 (best possible). The Sinhala version of the questionnaire demonstrated good internal consistency (a measure of the extent to which items in a questionnaire (sub)scale are correlated, thus measuring the same construct) in a previous study conducted in Sri Lanka [24]. We further calculated the internal consistency of the overall OPQOL-35 questionnaire in our study, and this was also estimated as good (alpha=0.86). Acceptable values of alpha range from 0.70 and 0.95 [35]. However, the internal consistency of the different domains varied from poor in the 'leisure activities and religion' domain (alpha=0.33) to good in the 'financial circumstances' domain (alpha=0.82) (Table 1). 
Table 1. Internal consistency of different domains of quality of life in OPQOL-35

questionnaire

\begin{tabular}{|c|c|c|}
\hline Domain & Questions representing each domain & $\begin{array}{c}\text { Cronbach's } \\
\text { alpha (n) }\end{array}$ \\
\hline D1- Life overall & $\begin{array}{l}\text { 1. I enjoy my life overall }(+) \\
\text { 2. I am happy much of the time }(+) \\
\text { 3. I look forward to things }(+) \\
\text { 4. Life gets me down }(-)\end{array}$ & $0.57(745)$ \\
\hline D2-Health & $\begin{array}{l}\text { 5. I have a lot of physical energy (+) } \\
\text { 6. Pain affects my well-being (-) } \\
\text { 7. My health restricts me looking after myself or my home (-) } \\
\text { 8. I am healthy enough to get out and about }(+)\end{array}$ & $0.80(746)$ \\
\hline $\begin{array}{l}\text { D3-Social } \\
\text { relationships and } \\
\text { participation }\end{array}$ & $\begin{array}{l}\text { 9. My family, friends or neighbours would help me if needed }(+) \\
\text { 10. I would like more companionship or contact with other people }(+) \\
\text { 11. I have someone who gives me love and affection }(+) \\
\text { 12. I would like more people to enjoy life with }(+) \\
\text { 13. I have my children around which is important }(+)\end{array}$ & $0.64(746)$ \\
\hline $\begin{array}{l}\text { D4-Independence, } \\
\text { control over life, } \\
\text { freedom }\end{array}$ & $\begin{array}{l}\text { 14. I am healthy enough to have my independence }(+) \\
\text { 15. I can please myself what I do (+) } \\
\text { 16. The cost of things compared to my pension/income restricts my life }(-) \\
\text { 17. I have a lot of control over the important things in my life }(+)\end{array}$ & $0.57(745)$ \\
\hline $\begin{array}{l}\text { D5-Home and } \\
\text { neighbourhood }\end{array}$ & $\begin{array}{l}\text { 18. I feel safe where I live }(+) \\
\text { 19. The local shops, services and facilities are good overall }(+) \\
\text { 20. I get pleasure from my home }(+) \\
\text { 21. I find my neighbourhood friendly }(+)\end{array}$ & $0.51(745)$ \\
\hline $\begin{array}{l}\text { D6-Psychological } \\
\text { and emotional } \\
\text { well-being }\end{array}$ & $\begin{array}{l}\text { 22. I take life as it comes and make the best of things }(+) \\
\text { 23. I feel lucky compared to most people }(+) \\
\text { 24. I tend to look on the bright side }(+) \\
\text { 25. If my health limits social/leisure activities, then I will compensate and find } \\
\text { something else I can do }(+)\end{array}$ & $0.52(742)$ \\
\hline $\begin{array}{l}\text { D7-Financial } \\
\text { circumstances }\end{array}$ & $\begin{array}{l}\text { 26. I have enough money to pay for household bills (+) } \\
\text { 27. I have enough money to pay for household repairs or help needed in the } \\
\text { house (+) } \\
28 \text {. I can afford to buy what I want to (+) } \\
29 \text {. I cannot afford to do things I would enjoy (-) }\end{array}$ & $0.82(746)$ \\
\hline $\begin{array}{l}\text { D8-Leisure } \\
\text { activities and } \\
\text { religion }\end{array}$ & $\begin{array}{l}\text { 30. I have social or leisure activities/hobbies that I enjoy doing }(+) \\
\text { 31. I try to stay involved with things }(+) \\
\text { 32. I do paid or unpaid work or activities that give me a role in life }(+) \\
\text { 33. I have responsibilities to others that restrict my social or leisure activities }(-) \\
\text { 34. Religion, belief or philosophy is important to my quality of life }(+) \\
\text { 35. Cultural/religious events/festivals are important to my quality of life }(+)\end{array}$ & $0.33(745)$ \\
\hline
\end{tabular}

(+) positively worded questions (-) negatively worded questions 


\section{Covariates}

Sociodemographic covariates of participants included sex, age at last birth day, ethnicity, marital status, living arrangements, education level (according to the International Standard Classification of Education [36]), longest-held income generation activity (according to the Sri Lanka Standard Classification of Occupation [37] based on the International Standard Classification of Occupations 2008 (ISCO-08)) [38] and subjective financial strain [39] and social support assessed using the Oslo-3 social support scale [40]. The total score of the Oslo3 social support scale ranged from 3-14 and participants were classified into three categories as follows: a score of 3-8 was classified as 'poor support', 9-11 as 'moderate support' and 1214 as 'strong support'. Health related variables included multimorbidity which was defined for the present study as co-existence of two or more concurrent chronic medical conditions $[41,42]$, existence of chronic pain in any part of the body, cognitive status assessed using Montreal Cognitive Assessment (MoCA) [43], and self-perceived vision and hearing ability assessed using a Likert scale. The total score of the MoCA ranged from 0-31, with higher scores representing higher cognition. All assessments have been validated in Sri Lanka $[44,45]$ except the Oslo-3 social support scale.

\section{Data collection and ethical considerations}

Five trained nursing graduates collected data from the entire sample through home visits. Participation for the study was voluntary and informed written consent was obtained from all participants. The ethical clearance for this study was obtained from two ethics review committees at University College London (Project ID: 8155/001) and Faculty of Medicine, University of Colombo, Sri Lanka (Protocol No. EC-16-071). 


\section{Statistical analyses}

All statistical analyses were performed in Stata version 15 accounting for complex survey design unless otherwise stated [46].

\section{Descriptive statistics}

Participants were stratified into three groups according to the lowest (76-127), intermediate (128-139) and highest (140-171) tertiles of the total OPQOL-35 score. Sociodemographic, health characteristics and frailty status of the overall sample and across the QoL tertiles were calculated using frequencies, percentages and medians (interquartile range, IQR) where appropriate. Unadjusted means (standard errors, SEs) of total and raw domain-specific quality of life scores were calculated and compared between the frailty groups using an adjusted Wald test. The maximum possible scores are not constant across the eight domains. Hence, standardised domain-specific mean scores were computed as follows: (unadjusted mean score /maximum possible score)*100 [24]. Therefore, the standardised scores have a minimum of 0 and maximum of 100 .

\section{Part I: association between frailty and overall QoL}

As missing data were minimal (2.3\%), a complete case analysis was performed. The total QoL score was found to be normally distributed and we therefore used linear regression models to estimate the unadjusted, 'age-and sex-adjusted' and multivariable-adjusted association between frailty status and overall QoL, with total QoL score as the dependent variable. Multivariable models were built by a step-wise addition of covariates to the 'ageand sex-adjusted' models. Variables included in the multivariable model were based a priori on the literature and clinical relevance. The final multivariable-adjusted model was further evaluated for model assumptions. Goodness of fit ( $\mathrm{R}^{2}$ statistic) was reported. 


\section{Part II: Association between frailty and domain-specific QoL}

We fitted further multivariable linear regression models to explore how the different domains of QoL were associated with frailty and pre-frailty. All models were adjusted for the covariates used in the final multivariable model of the part I analysis.

For parts I and II, we present the results using the estimated difference in means between frailty groups (with the robust group as reference category) and also computed the reduction from the maximum possible score as a percentage as follows: (mean difference in QoL score /maximum possible score)*100.

\section{Results}

\section{Data screening and missing values}

Of 750 persons approached, 746 participated in the study. We could not determine the frailty status of one participant due to missing data on frailty components. Therefore, that participant was excluded from the analysis. The total QoL score was missing for seven participants as they had missing data for one or more domain-specific scores. Of all covariates, chronic pain and social support score were missing for seven and four participants respectively.

\section{Sociodemographic, health characteristics and frailty status of the overall sample and by OPQOL-35 score tertiles}

The median (IQR) age of the sample was 68 (64: 75) years. The sample was 56.7\% women and the majority (97.4\%) were Sinhalese ethnicity and had lower secondary or above education level (71.3\%). The median (IQR) cognitive assessment (MoCA) score of the sample was 20 (15: 23). According to the Fried phenotype of frailty, 15.2\% (95\% CI: 12.4\%, 
$18.7 \%$ ) of study participants were frail, $48.5 \%$ (95\% CI: $43.9 \%, 53.2 \%)$ were pre-frail and $36.2 \%$ (95\% CI: $32.4 \%, 40.3 \%$ ) were robust. A higher proportion of men were in the highest QoL tertile compared with women (36.6\% and 30.6\% respectively). $82.4 \%$ of older adults in the 'poor' social support category were in the lowest QoL tertile. (Table 2). The median (IQR) cognitive assessment (MoCA) scores of older adults in the lowest, intermediate and highest QoL tertiles were 16 (12:20), 20 (16: 23) and 22 (19: 24) respectively. $47.5 \%$ of participants in the robust group were in the highest QoL tertile compared with $9.6 \%$ of participants in the frail group. 
Table 2. Sociodemographic, health characteristics and frailty status of the overall sample and by OPQOL-35 score tertiles

\begin{tabular}{|c|c|c|c|c|c|}
\hline \multirow[t]{2}{*}{ Covariate } & \multirow{2}{*}{$\begin{array}{c}\text { Unweighted } \\
\text { sample } \\
\%^{a},(n)\end{array}$} & \multirow{2}{*}{$\begin{array}{c}\text { Weighted } \\
\text { sample } \\
(\%)^{\mathrm{a}}\end{array}$} & \multicolumn{3}{|c|}{$\begin{array}{l}\text { Weighted percentage }(\%)^{b} \\
\text { (OPQOL-35 score tertiles) }\end{array}$} \\
\hline & & & Lowest & Intermediate & Highest \\
\hline \multicolumn{6}{|l|}{ Sex } \\
\hline Men & $46.8(349)$ & 43.3 & 29.1 & 34.3 & 36.6 \\
\hline Women & $53.2(396)$ & 56.7 & 37.7 & 31.7 & 30.6 \\
\hline \multicolumn{6}{|l|}{ Age category (years) } \\
\hline $60-64$ & $33.3(248)$ & 35.7 & 23.1 & 37.0 & 39.9 \\
\hline $65-69$ & 26.7 (199) & 25.3 & 26.8 & 37.4 & 35.8 \\
\hline $70-74$ & $13.3(99)$ & 17.0 & 44.5 & 28.2 & 27.3 \\
\hline $75-79$ & $13.4(100)$ & 11.2 & 55.5 & 24.8 & 19.7 \\
\hline$\geq 80$ & $13.3(99)$ & 10.8 & 48.1 & 24.0 & 27.9 \\
\hline \multicolumn{6}{|l|}{ Ethnicity } \\
\hline Sinhalese & $96.9(722)$ & 97.4 & 34.0 & 32.8 & 33.2 \\
\hline Other & $3.1(23)$ & 2.6 & 33.2 & 34.0 & 32.8 \\
\hline \multicolumn{6}{|l|}{ Marital status } \\
\hline Married/cohabiting & $61.3(457)$ & 59.6 & 29.1 & 34.1 & 36.8 \\
\hline Never-married/widowed/separated/divorced & $38.7(288)$ & 40.4 & 41.3 & 31.0 & 27.7 \\
\hline \multicolumn{6}{|l|}{ Living arrangement } \\
\hline Children/other family & $82.7(616)$ & 82.9 & 33.1 & 33.1 & 33.8 \\
\hline With spouse only & $11.3(84)$ & 10.8 & 29.0 & 33.8 & 37.2 \\
\hline Alone & $6.0(45)$ & 6.3 & 53.3 & 28.5 & 18.2 \\
\hline \multicolumn{6}{|l|}{ Social support } \\
\hline Poor & $4.3(32)$ & 4.3 & 82.4 & 15.3 & 2.3 \\
\hline Moderate & $16.7(124)$ & 16.7 & 58.1 & 23.3 & 18.6 \\
\hline Strong & $79.0(585)$ & 79.0 & 26.4 & 35.6 & 38.0 \\
\hline \multicolumn{6}{|l|}{ Education level } \\
\hline No formal education/primary & $28.7(214)$ & 28.7 & 48.3 & 33.2 & 18.5 \\
\hline Lower secondary & $35.2(262)$ & 35.3 & 34.3 & 37.7 & 28.0 \\
\hline Upper secondary or above & $36.1(269)$ & 36.0 & 22.1 & 27.8 & 50.1 \\
\hline \multicolumn{6}{|l|}{ Longest-held occupation } \\
\hline Never-employed/skill level 1 & $42.4(316)$ & 43.8 & 43.6 & 32.7 & 23.7 \\
\hline Skill level 2 & $39.3(293)$ & 38.5 & 31.4 & 38.0 & 30.6 \\
\hline Skill level 3 or 4 & $18.3(136)$ & 17.7 & 15.7 & 22.0 & 62.3 \\
\hline \multicolumn{6}{|l|}{ Perceived financial strain } \\
\hline Finding it difficult/very difficult & $20.4(152)$ & 20.4 & 59.4 & 29.6 & 11.0 \\
\hline Just about getting by & $54.5(406)$ & 55.0 & 32.5 & 37.2 & 30.3 \\
\hline Living comfortably & $25.1(187)$ & 24.6 & 16.7 & 25.7 & 57.6 \\
\hline \multicolumn{6}{|l|}{ Multimorbidity } \\
\hline No & $59.1(440)$ & 58.6 & 30.2 & 30.3 & 39.5 \\
\hline Yes & $40.9(305)$ & 41.4 & 39.3 & 36.5 & 24.2 \\
\hline \multicolumn{6}{|l|}{ Chronic pain } \\
\hline No & $42.4(313)$ & 41.3 & 19.0 & 30.6 & 50.4 \\
\hline Yes & $57.6(425)$ & 58.7 & 44.8 & 34.7 & 20.5 \\
\hline \multicolumn{6}{|l|}{ Self-perceived vision ability } \\
\hline Poor/Fair & $50.9(379)$ & 50.0 & 44.8 & 30.2 & 25.0 \\
\hline Good/Very good/Excellent & $49.1(366)$ & 50.0 & 23.2 & 35.5 & 41.3 \\
\hline \multicolumn{6}{|l|}{ Self-perceived hearing ability } \\
\hline Poor/Fair & $34.0(253)$ & 32.8 & 42.7 & 29.3 & 28.0 \\
\hline Good/Very good/Excellent & $66.0(492)$ & 67.2 & 29.7 & 34.6 & 35.7 \\
\hline \multicolumn{6}{|l|}{ Frailty status } \\
\hline Robust & $35.0(261)$ & 36.3 & 11.5 & 41.0 & 47.5 \\
\hline Pre-frail & $48.7(363)$ & 48.5 & 37.7 & 32.4 & 29.9 \\
\hline Frail & $16.3(121)$ & 15.2 & 75.8 & 14.6 & 9.6 \\
\hline
\end{tabular}




\section{Distribution of total and domain-specific quality of life scores according to frailty status}

Fig 1 illustrates the distribution of the total QoL score according to frailty status. The median QoL score decreased across the frailty spectrum. The unadjusted means (SE) of the total QoL score for the robust, pre-frail and frail groups were $139.2(0.64), 131.8(1.04)$ and 119.2 (1.35) respectively (Table 3$)$.

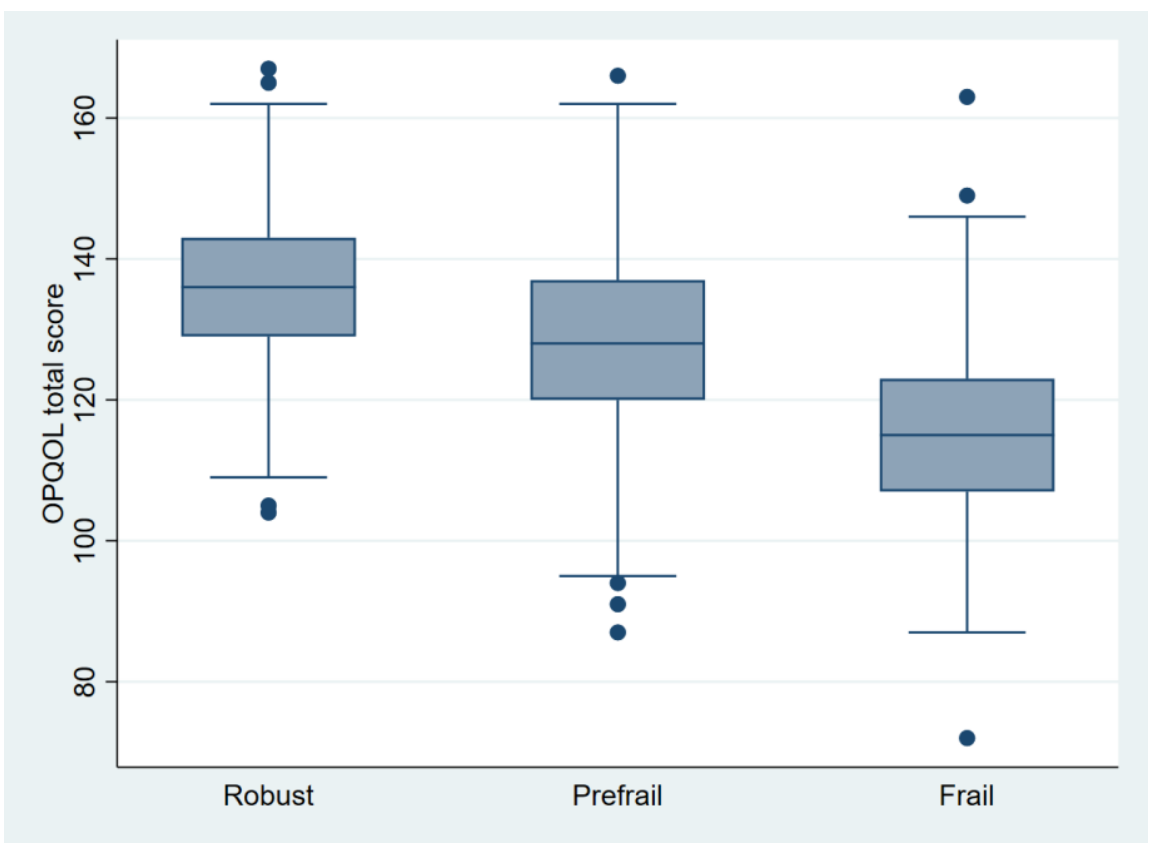

Fig 1 Distribution of total quality of life score according to frailty status

Participants in the frail group had on average a worse total QoL score compared with their pre-frail and robust counterparts (Table 3). According to this unadjusted mean comparison, all domains were associated with frailty except 'social relationships and participation' and 'home and neighbourhood'. Appendix I reports the distribution of domain-specific QoL scores according to frailty status. Fig 2 shows the standardised domain-specific unadjusted mean scores by frailty status. 
Table 3. Unadjusted mean comparison of total and domain-specific QoL scores according to frailty status.

\begin{tabular}{|l|r|r|r|r|}
\hline \multicolumn{1}{|c|}{ Domain } & \multicolumn{2}{|c|}{ Weighted mean (SE) } & p-value \\
\cline { 2 - 5 } & \multicolumn{1}{|c|}{ Robust } & \multicolumn{1}{|c|}{ Pre-frail } & \multicolumn{1}{|c|}{ Frail } & \\
\hline Total OPQOL-35 score (score 35-175) & $139.2(0.64)$ & $131.8(1.04)$ & $119.2(1.35)$ & $<0.001$ \\
\hline Life overall (score 4-20) & $15.2(0.18)$ & $14.3(0.12)$ & $12.9(0.22)$ & 0.007 \\
\hline Health (score 4-20) & $15.4(0.19)$ & $13.1(0.18)$ & $8.4(0.29)$ & $<0.001$ \\
\hline $\begin{array}{l}\text { Social relationships and participation } \\
\text { (score 5-25) }\end{array}$ & $21.2(0.15)$ & $21.1(0.16)$ & $21.0(0.26)$ & 0.777 \\
\hline $\begin{array}{l}\text { Independence, control over life and } \\
\text { freedom (score 4-20) }\end{array}$ & $15.7(0.12)$ & $14.4(0.17)$ & $11.4(0.24)$ & $<0.001$ \\
\hline Home and neighbourhood (score 4-20) & $16.4(0.20)$ & $16.1(0.18)$ & $15.8(0.21)$ & 0.252 \\
\hline $\begin{array}{l}\text { Psychological and emotional wellbeing } \\
\text { (score 4-20) }\end{array}$ & $16.5(0.12)$ & $16.1(0.14)$ & $15.1(0.18)$ & 0.005 \\
\hline Financial circumstances (score 4-20) & $13.5(0.21)$ & $12.1(0.32)$ & $11.3(0.42)$ & 0.010 \\
\hline Leisure activities and religion (score 6-30) & $25.0(0.16)$ & $24.5(0.16)$ & $23.2(0.33)$ & 0.018 \\
\hline
\end{tabular}

${ }^{\ddagger}$ p-values for mean difference calculated using Wald tests adjusted for complex sampling design.

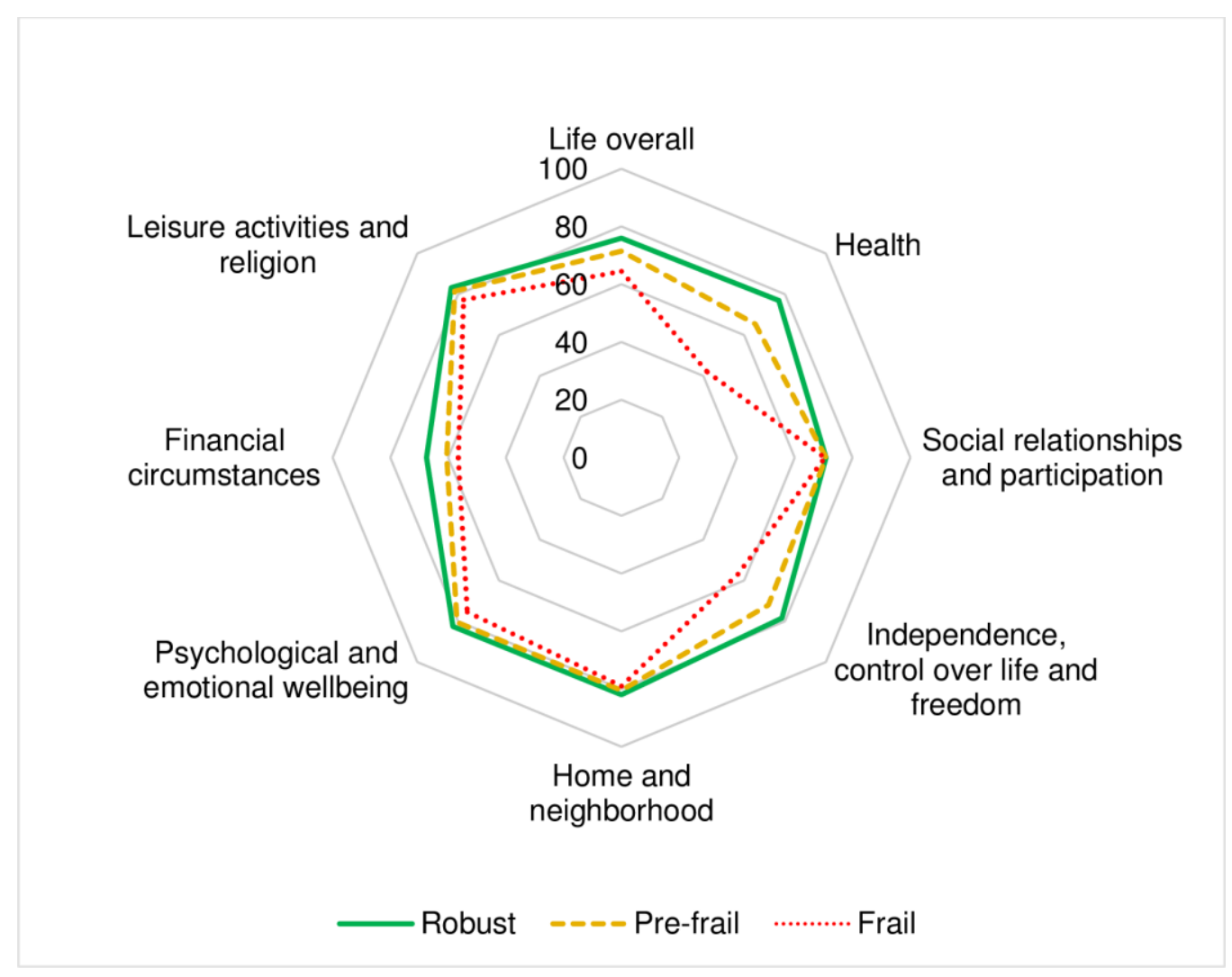

Fig 2 Standardised domain-specific unadjusted mean scores by frailty status 


\section{Part I: Association between frailty and total QoL}

Table 4 presents the association between frailty and pre-frailty with the total QoL score in unadjusted, 'age-and sex-adjusted' and five multivariable linear regression models adjusted for different covariates at each stage. In the unadjusted model, the estimated mean difference of the QoL score between the frail and robust groups was -20.0 (95\% CI: -23.3, -16.7) points, an $11.4 \%$ reduction from the maximum possible score of the scale (175). However, the mean difference in QoL scores was gradually attenuated with the addition of other covariates that are associated with both frailty and poor QoL. The final model showed an association of frailty with total QoL after adjusting for other sociodemographic covariates, multimorbidity, chronic pain, cognitive assessment score and self-perceived vision and hearing ability. The estimated reduction in the total QoL score between the frail and robust groups was -12.7 $(-16.3,-9.0)$ points, a $7.3 \%$ reduction from the maximum possible score. Similarly, there was a significant association between pre-frailty and total QoL in the final multivariable model. The estimated reduction in the total QoL score between the pre-frail and robust groups was $3.7(-6.4,-1.1)$ points, a $2.1 \%$ reduction from the maximum possible score. Appendix II presents the full results of each model (model 1 to model 7) reported in Table 4. 
Table 4. Multivariable linear regression models: association between pre-frailty, frailty and total quality of life

\begin{tabular}{l|l|c|c|}
\hline \multicolumn{1}{|c|}{ Model } & \multicolumn{1}{c|}{ Coefficient $\mathbf{9 5 \%}$ CI) } & \multirow{2}{*}{$\mathbf{R}^{\mathbf{2}} \mathbf{( \% )}$} \\
\cline { 2 - 4 } & Pre-frailty & Frailty & \\
\hline Model 1: Unadjusted & $-7.4(-10.0,-4.8)$ & $-20.0(-23.3,-16.7)$ & 20.3 \\
\hline Model 2: Model 1+ age and sex & $-6.9(-9.5,-4.4)$ & $-19.8(-23.3,-16.3)$ & 21.5 \\
\hline Model 3: Model 2+ longest-held occupation & $-6.3(-8.7,-3.9)$ & $-18.0(-21.9,-14.1)$ & 26.3 \\
\hline Model 4: Model 3+ social support & $-5.3(-7.9,-2.6)$ & $-16.0(-20.0,-12.1)$ & 33.6 \\
\hline Model 5: Model 4+ multimorbidity, chronic pain & $-4.5(-7.3,-1.8)$ & $-14.5(-18.1,-10.9)$ & 37.0 \\
\hline Model 6: Model 5+ cognitive assessment score & $-3.9(-6.4,-1.3)$ & $-12.9(-16.4,-9.5)$ & 39.1 \\
\hline Model 7: Model 6+ perceived vision and hearing & $-3.7(-6.4,-1.1)$ & $-12.7(-16.3,-9.0)$ & 39.3 \\
\hline ability & & & \\
\hline
\end{tabular}

\section{Part II: Association between frailty and domain-specific quality of life}

After adjusting for covariates in the final multivariable model in the main analysis (model 7 in Table 4), the estimated difference in means were lower for the frail group versus robust group in the 'life overall', 'health' and 'independence, control over life and freedom', 'psychological and emotional wellbeing' and 'leisure activities and religion' domains. Likewise, the estimated difference in means were lower for the pre-frail group versus robust group in the 'health', 'independence, control over life and freedom' and 'financial circumstances' domains (Table 5). Full results can be found in appendix III.

Of six domains associated with frailty, the 'health' and 'independence, control over life and freedom' domains appeared to have the largest reduction in sub-scale score. In the multivariable model, the estimated mean difference in the 'health' domain score between participants in the frail and robust groups was -5.36 (27.0\% reduction in maximum possible sub-scale score). We performed a sensitivity analysis excluding the question "I have a lot of physical energy" from the 'health' domain as it was highly related to the self-reported 
exhaustion component of the frailty assessment. This did not change the reduction in the health domain sub-scale score.

Table 5. Domains of quality of life associated with pre-frailty and frailty

\begin{tabular}{|c|c|c|c|}
\hline \multirow[t]{2}{*}{ Domain of quality of life } & \multicolumn{2}{|c|}{ Coefficient $(95 \% \text { CI })^{\dagger}$} & \multirow[t]{2}{*}{$\mathbf{R}^{2}(\%)$} \\
\hline & Pre-frailty & Frailty & \\
\hline Health & $-1.43(-1.98,-0.88)$ & $-5.36(-6.19,-4.54)$ & 49.1 \\
\hline Independence, control over life and freedom & $-0.64(-1.15,-0.13)$ & $-2.93(-3.72,-2.14)$ & 40.1 \\
\hline Financial circumstances & $-0.83(-1.52,-0.13)$ & $-0.96(-1.95,0.03)$ & 25.2 \\
\hline Life overall & $-0.43(-0.95,0.07)$ & $-1.39(-2.14,-0.63)$ & 20.0 \\
\hline Psychological and emotional wellbeing & $-0.16(-0.62,0.28)$ & $-0.97(-1.56,-0.38)$ & 14.3 \\
\hline Home and neighbourhood & $-0.01(-0.57,0.54)$ & $-0.17(-0.86,0.52)$ & 10.9 \\
\hline Leisure activities and religion & $-0.18(-0.63,0.27)$ & $-1.09(-1.99,-0.19)$ & 10.6 \\
\hline Social relationships and participation & $0.18(-0.40,0.77)$ & $0.38(-0.42,1.17)$ & 10.0 \\
\hline
\end{tabular}

\section{Discussion}

\section{Summary of main findings}

The results of this study demonstrate that frailty and pre-frailty were associated with lower quality of life in rural community-dwelling older adults in Kegalle district of Sri Lanka, and this remained after adjustment for a range of covariates. However, while statistically significant in the fully adjusted model, the contribution of frailty and pre-frailty was small ( $7.3 \%$ and $2.1 \%$ reduction respectively from the maximum possible total score). Of the eight domains of QoL, five domains were associated with frailty and three domains were associated with pre-frailty in rural Sri Lankan older adults. 


\section{Comparison with the existing literature}

Our findings corroborate the findings of previous studies: frailty and/or pre-frailty were significantly associated with lower QoL or HRQoL compared with robust older adults $[14,6,11]$. However, direct comparisons of our findings with these studies is not feasible due to the differences in study methodology; mainly the method of assessment of frailty and QoL/HRQoL, study participants and analysis techniques. Previous studies that have estimated the associations between frailty and HRQoL adjusted for several covariates [8-10]. However, we only found one study (conducted by Bilotta and colleagues) that had attempted to estimate the association between frailty and the broader concept of QoL after adjusting for other covariates [14].

In a similar study to ours, Bilotta and colleagues conducted a study with community-dwelling older adults referred to an outpatient geriatric clinic in Milan, Italy [14]. They used the same QoL instrument as used in our study but used a different frailty evaluation method (Study of Osteoporotic Fractures (SOF) criteria). QoL tertiles and respective ranges were lower compared to our study. Findings of the unadjusted analysis reported that of the eight QoL domains, all were associated with frailty except 'social relationships and participation' and 'financial circumstances'. In our unadjusted mean comparison, all the QoL domains were associated with frailty except 'social relationships and participation' and 'home and neighbourhood'. Bilotta and colleagues also constructed a multivariable linear regression model; with OPQOL total as the dependent variable and the following as independent variables: frailty status, age, basic activities of daily living, instrumental activities of daily living, cognitive status (assessed with the Mini-Mental State Examination instrument), depression, comorbidity (assessed by means of the Cumulative Illness Rating Scale), any fall in the past year, and number of drugs taken. Frailty (as assessed by SOF criteria) was 
associated with a lower OPQOL total: $-6.36(95 \%$ CI: -10.37 to -2.35$)$ compared with robust in this multivariable adjusted model. The $\mathrm{R}^{2}$ of the model was $32.0 \%$. The estimated mean difference of the QoL score between the frail and robust groups in this study was smaller compared with our study. This can at least be partly explained by the difference in the frailty assessment method used and the different set of covariates included in the final multivariable model.

A study conducted in Mexico reported that the perception of QoL was lower among community-dwelling frail older adults identified with the Fried phenotype compared with pre-frail and non-frail older adults with both generic HRQoL (SF-36) and specific (WHOQOL-OLD) QoL instruments. The lowest mean scores were observed for the frail group followed by the pre-frail group for the total score and for all the sub domains of both instruments [11].

\section{Strengths and limitations}

To the best of our knowledge, this is the first study conducted in the World Health Organization South-East Asian region to assess the association of frailty with quality of life. We conducted this study with a large representative sample of community-dwelling older adults with a high response rate (99.5\%). We used the Fried phenotype frailty assessment method which is used extensively and has been shown to have good predictive validity [1] and we used a quality of life questionnaire specifically designed to assess the overall QoL of older adults (OPQOL). However, use of this questionnaire to assess the association of frailty with QoL is still scarce, limiting direct comparisons with studies in other settings. Older age, poor financial situation, poor social support, multimorbidity, chronic pain, cognitive impairment, and hearing and vision impairment are associated with both frailty and lower 
QoL scores [47-58]. We therefore adjusted our final regression model for all these variables to estimate the independent association of frailty with QoL. We did not include further adjustment for depression and functional impairment as we felt that these factors are potentially on the causal pathway between frailty and QoL. However, the cross-sectional nature of the study design does not allow us to establish temporal relationships or causality.

We did not have access to valid repeated weight measures to calculate unintentional weight loss. Therefore, shrinking was operationalised as having a body mass index (BMI) $<18.5 \mathrm{~kg} / \mathrm{m}^{2}$. This is often used as a measure for being underweight rather than shrinking/unintentional weight loss and is a different construct to the original proposed by Fried and colleagues [1], though it has been widely used in the literature [59]. Ethnic homogeneity (Sinhalese) and having a sample exclusively drawn from the rural areas limit the generalisability of findings across older adults from other ethnic groups and urban and estate areas in Sri Lanka. The internal consistency for the overall OPQOL-35 questionnaire was estimated as good in our study. However, not all the QoL domains reported satisfactory internal consistency. Values of Cronbach's alpha (a common measure of internal consistency) are affected by the length of the instrument, for instance, if an instrument has a higher number of items, the alpha values tended to be higher. Low values of alpha could be due to the low number of items, poor inter-relatedness between items, or heterogeneous constructs [60]. Therefore, a comprehensive psychometric evaluation including the structural validity of the OPQOL-35 questionnaire in Sri Lankan context is warranted. Our part II analysis included multiple testing and were performed for exploratory purposes only; therefore our findings should be interpreted with caution. 


\section{Implications for health, social services and future research}

We found a smaller than expected (though still significant) reduction of QoL associated with frailty. This may be due to the strong social support systems in Sri Lankan rural society that mitigate the non-health impacts of frailty in older adults. Due to existing strong family support, institutionalised mechanisms for care of the elderly has not been widely established. With the demographic and social transformations happening in the country and the region, sustainability of informal support systems is doubtful. The association between frailty and QoL appears to be largely explained by 'health' and 'independence, control over life and freedom' domains. Health services for older adults with frailty should consider ways they can maximise independence and life control as well as optimising their health. Further work should explore more in-depth associations between frailty and QoL e.g. how factors such as depression and limitations of instrumental and basic activities of daily living mediate this association.

\section{Conclusions}

Frailty was associated with a small but significantly lower quality of life in this rural Sri Lankan population of older adults. This was largely explained by 'health' and 'independence, control over life and freedom' domains in our sample. Interventions aiming to improve quality of life in frail older adults should consider targeting these aspects.

\section{Acknowledgements}

Authors acknowledge all the participants of this study who kindly gave their time and effort to respond the questionnaire. We also thank the assistance provided by the Director General of Health Services, Provincial Director of Health Services-Sabaragamuwa province, District 
Secretary and Regional Director of Health Services-Kegalle district, all the Divisional secretaries and the Grama Niladhari officers of the respective areas investigated in this study. We would also like to thank Mrs. Krishna Kurunathapillai for performing the Tamil translation of all the study instruments. We would like to thank the research assistants (H.P.M. Hewavitharane, P.G.I.P. Udayakumara, D.M.N. Kumara, A.P.A. Jayasinghe, M.V.J.D. Abeyrathna) and the field assistants (H.K.P. Ariyadasa, K.D.S.S. Dissanayaka, W.G.C. Pussallamada, G.R.K.M. Rathnasiri, W.S.T. Weerasinghe, R.J.S. Dharmawansha, W.R.P. Wijenayake, V.P.D.I. Danarathna, R.G.R.D. Anuruddha) for their invaluable support with data collection. We would also like to acknowledge Prof. A.R. Wickremasinghe, Department of Public Health, Faculty of Medicine, University of Kelaniya, Sri Lanka for his invaluable guidance on data cleaning process. We thank Department of Community Medicine, Faculty of Medicine, University of Colombo for handling finances and arranging logistics for the field study.

Funding: DDS (corresponding author) is a commonwealth Scholar, funded by UK government (LKCS-2015-678). This funder had no role in study design, data collection, data analysis, interpretation, drafting the paper, or decision to publish.

Author contributions: DDS, KW, MCW, GR conceived and designed the study. DDS and MCW collected the data. DDS and SS analysed the data. DDS drafted the manuscript. KW, MCW, GR, SS critically revised the manuscript.

\section{Conflict of interest}

The authors declare that they have no conflict of interest. 


\section{Ethical approval}

All procedures performed in studies involving human participants were in accordance with the ethical standards of the institution or practice at which the study was conducted. The ethical clearance for this study was obtained from two ethics review committees at University College London (Project ID: 8155/001) and Faculty of Medicine, University of Colombo, Sri Lanka (Protocol No. EC-16-071).

\section{Informed consent}

Informed written consent was obtained from all individual participants included in the study.

\section{References}

1. Fried, L. P., Tangen, C. M., Walston, J., Newman, A. B., Hirsch, C., Gottdiener, J., et al. (2001). Frailty in Older Adults: Evidence for a Phenotype. The Journals of Gerontology: Series A, 56(3), M146-M157, doi:10.1093/gerona/56.3.M146.

2. Vermeiren, S., Vella-Azzopardi, R., Beckwée, D., Habbig, A.-K., Scafoglieri, A., Jansen, B., et al. (2016). Frailty and the Prediction of Negative Health Outcomes: A Meta-Analysis. Journal of the American Medical Directors Association, 17(12), 1163.e1161-1163.e1117, doi:https://doi.org/10.1016/j.jamda.2016.09.010.

3. Gale, C. R., Cooper, C., Deary, I. J., \& Aihie Sayer, A. (2013). Psychological well-being and incident frailty in men and women: the English Longitudinal Study of Ageing. Psychological Medicine, 44(4), 697-706, doi:10.1017/S0033291713001384.

4. Collard, R. M., Boter, H., Schoevers, R. A., \& Oude Voshaar, R. C. (2012). Prevalence of Frailty in Community-Dwelling Older Persons: A Systematic Review. Journal of the American Geriatrics Society, 60(8), 1487-1492, doi:10.1111/j.1532-5415.2012.04054.x.

5. Siriwardhana, D. D., Hardoon, S., Rait, G., Weerasinghe, M. C., \& Walters, K. R. (2018). Prevalence of frailty and prefrailty among community-dwelling older adults in low-income and middleincome countries: a systematic review and meta-analysis. [10.1136/bmjopen-2017-018195]. BMJ Open, 8(3), doi:10.1136/bmjopen-2017-018195.

6. Kojima, G., Iliffe, S., Jivraj, S., \& Walters, K. (2016). Association between frailty and quality of life among community-dwelling older people: a systematic review and meta-analysis. [10.1136/jech-2015-206717]. Journal of epidemiology and community health.

7. Mulasso, A., Roppolo, M., \& Rabaglietti, E. (2014). The role of individual characteristics and physical frailty on health related quality of life (HRQOL): A cross sectional study of Italian community-dwelling older adults. Archives of Gerontology and Geriatrics, 59(3), 542-548, doi:https://doi.org/10.1016/j.archger.2014.08.012.

8. Chang, Y.-W., Chen, W.-L., Lin, F.-G., Fang, W.-H., Yen, M.-Y., Hsieh, C.-C., et al. (2012). Frailty and Its Impact on Health-Related Quality of Life: A Cross-Sectional Study on Elder Community- 
Dwelling Preventive Health Service Users. PLoS ONE, 7(5), e38079, doi:10.1371/journal.pone.0038079.

9. Lin, C.-C., Li, C.-I., Chang, C.-K., Liu, C.-S., Lin, C.-H., Meng, N.-H., et al. (2011). Reduced HealthRelated Quality of Life in Elders with Frailty: A Cross-Sectional Study of Community-Dwelling Elders in Taiwan. PLOS ONE, 6(7), e21841, doi:10.1371/journal.pone.0021841.

10. Masel, M. C., Graham, J. E., Reistetter, T. A., Markides, K. S., \& Ottenbacher, K. J. (2009). Frailty and health related quality of life in older Mexican Americans. Health and Quality of Life Outcomes, 7, 70-70, doi:10.1186/1477-7525-7-70.

11. Sánchez-García, S., Gallegos-Carrillo, K., Espinel-Bermudez, M. C., Doubova, S. V., SánchezArenas, R., García-Peña, C., et al. (2017). Comparison of quality of life among communitydwelling older adults with the frailty phenotype. Quality of Life Research, 26(10), 2693-2703, doi:10.1007/s11136-017-1630-5.

12. Lin, X.-J., Lin, I. M., \& Fan, S.-Y. (2013). Methodological issues in measuring health-related quality of life. Tzu Chi Medical Journal, 25(1), 8-12, doi:https://doi.org/10.1016/j.tcmj.2012.09.002.

13. Hambleton, P., Keeling, S., \& McKenzie, M. (2009). The jungle of quality of life: Mapping measures and meanings for elders. Australasian Journal on Ageing, 28(1), 3-6, doi:10.1111/j.1741-6612.2008.00331.x.

14. Bilotta, C., Bowling, A., Casè, A., Nicolini, P., Mauri, S., Castelli, M., et al. (2010). Dimensions and correlates of quality of life according to frailty status: a cross-sectional study on communitydwelling older adults referred to an outpatient geriatric service in Italy. Health and Quality of Life Outcomes, 8, 56-56, doi:10.1186/1477-7525-8-56.

15. Lin, Y.-C., Chang, J.-C., Chen, Y.-M., Li, C.-M., \& Huang, L.-H. (2017). Health Related Quality of Life Among Frail and Pre-Frail Older Adults in Taiwan. International Journal of Gerontology, 11(4), 249-252, doi:https://doi.org/10.1016/j.ijge.2017.01.003.

16. Gobbens, R. J. J., Luijkx, K. G., \& van Assen, M. A. L. M. (2013). Explaining quality of life of older people in the Netherlands using a multidimensional assessment of frailty. Quality of Life Research, 22(8), 2051-2061, doi:10.1007/s11136-012-0341-1.

17. Hubbard, R. E., Goodwin, V. A., Llewellyn, D. J., Warmoth, K., \& Lang, I. A. (2014). Frailty, financial resources and subjective well-being in later life. Archives of Gerontology and Geriatrics, 58(3), 364-369, doi:https://doi.org/10.1016/j.archger.2013.12.008.

18. Hyde, M., Wiggins, R. D., Higgs, P., \& Blane, D. B. (2003). A measure of quality of life in early old age: The theory, development and properties of a needs satisfaction model (CASP-19). Aging \& Mental Health, 7(3), 186-194, doi:10.1080/1360786031000101157.

19. Marshall, P. A. (1990). Cultural influences on perceived quality of life. Seminars in Oncology Nursing, 6(4), 278-284, doi:https://doi.org/10.1016/0749-2081(90)90030-9.

20. Perera, B. (2011). Social support and social security issues of elders in Sri Lanka. Galle Medical Journal, 16(2), 20-23.

21. Ministry of Health Nutrition and Indigenous Medicine, \& World Health Organization (2015). Non Communicable Disease Risk Factor Survey Sri Lanka 2015.

22. De silva, W. I. (2007). A Population projection of Sri Lanka for the Millenium, 2001 - 2101: Trends and Implications.

23. Khaltar, A., Priyadarshani, N. G. W., Delpitiya, N. Y., Jayasinghe, C., Jayasinghe, A., Arai, A., et al. (2017). Depression among older people in Sri Lanka: With special reference to ethnicity. Geriatrics and Gerontology International, 17(12), 2414-2420, doi:10.1111/ggi.13090.

24. Rathnayake, S., \& Siop, S. (2015). Indian Journal of Gerontology. Quality of Life and Its Determinants among Older People Living in the Rural Community in Sri Lanka, 29(2), 131153.

25. Damayanthi, H. D. W. T., Moy, F. M., Abdullah, K. L., \& Dharmaratne, S. D. (2018). Health related quality of life and its associated factors among community-dwelling older people in Sri Lanka: A cross-sectional study. Archives of Gerontology and Geriatrics, 76, 215-220, doi:https://doi.org/10.1016/j.archger.2018.03.009. 
26. Lemeshow, S., Hosmer, D. W., Klar, J., Lwanga, S. K., \& World Health Organization (1990). Adequacy of sample size in health studies. Baffins Lane, Chichester, West Sussex P019 1 UD, England John Wiley \& Sons Ltd.

27. Jotheeswaran, A. T., Bryce, R., Prina, M., Acosta, D., Ferri, C. P., Guerra, M., et al. (2015). Frailty and the prediction of dependence and mortality in low- and middle-income countries: A 10/66 population-based cohort study. BMC Medicine, 13 (1) (no pagination)(138), doi:http://dx.doi.org/10.1186/s12916-015-0378-4.

28. Katz, J., \& Zeger, S. L. (1994). Estimation of design effects in cluster surveys. Annals of Epidemiology, 4(4), 295-301, doi:https://doi.org/10.1016/1047-2797(94)90085-X.

29. Siriwardhana, D. D., Weerasinghe, M. C., Rait, G., Falcaro, M., Scholes, S., \& Walters, K. R. (2019). Prevalence of frailty in rural community-dwelling older adults in Kegalle district of Sri Lanka: a population-based cross-sectional study. BMJ Open, 9(1), bmjopen-2018-026314, doi:10.1136/bmjopen-2018-026314.

30. Radloff, L. S. (1977). The CES-D Scale: A Self-Report Depression Scale for Research in the General Population. Applied Psychological Measurement, 1(3), 385-401, doi:10.1177/014662167700100306.

31. Craig, C. L., Marshall, A. L., SjÖStrÖM, M., Bauman, A. E., Booth, M. L., Ainsworth, B. E., et al. (2003). International Physical Activity Questionnaire: 12-Country Reliability and Validity. Medicine \& Science in Sports \& Exercise, 35(8).

32. Bowling, A. (2009). The Psychometric Properties of the Older People's Quality of Life Questionnaire, Compared with the CASP-19 and the WHOQOL-OLD. Current Gerontology and Geriatrics Research, 2009, 298950, doi:10.1155/2009/298950.

33. Bowling, A. (2009). Perceptions of active ageing in Britain: divergences between minority ethnic and whole population samples. Age and Ageing, 38(6), 703-710, doi:10.1093/ageing/afp175.

34. Bowling, A., \& Stenner, P. (2011). Which measure of quality of life performs best in older age? A comparison of the OPQOL, CASP-19 and WHOQOL-OLD. [10.1136/jech.2009.087668]. Journal of epidemiology and community health, 65(3), 273.

35. Terwee, C. B., Bot, S. D. M., de Boer, M. R., van der Windt, D. A. W. M., Knol, D. L., Dekker, J., et al. (2007). Quality criteria were proposed for measurement properties of health status questionnaires. Journal of Clinical Epidemiology, 60(1), 34-42, doi:https://doi.org/10.1016/i.jclinepi.2006.03.012.

36. United Nations Educational Scientific and Cultural Organization (2012). International Standard Classification of Education ISCED 2011. P.O. Box 6128, Succursale Centre-Ville, Montreal, Quebec H3C 3J7, Canada.

37. Department of Census and Statistics (2008). Sri Lanka standard classification of occupation (SLSCO - 08).

38. International Labour Office (2012). International Standard Classification of Occupations ISCO-08. (Vol. I).

39. Weich, S., \& Lewis, G. (1998). Poverty, unemployment, and common mental disorders: population based cohort study. [10.1136/bmj.317.7151.115]. BMJ, 317(7151), 115.

40. Dalgard, O. S., Dowrick, C., Lehtinen, V., Vazquez-Barquero, J. L., Casey, P., Wilkinson, G., et al. (2006). Negative life events, social support and gender difference in depression. Social Psychiatry and Psychiatric Epidemiology, 41(6), 444-451, doi:10.1007/s00127-006-0051-5.

41. van den Akker, M., Buntinx, F., \& Knottnerus, J. A. (1996). Comorbidity or multimorbidity. European Journal of General Practice, 2(2), 65-70, doi:10.3109/13814789609162146.

42. Uijen, A. A., \& van de Lisdonk, E. H. (2008). Multimorbidity in primary care: Prevalence and trend over the last 20 years. European Journal of General Practice, 14(sup1), 28-32, doi:10.1080/13814780802436093.

43. Nasreddine, Z. S., Phillips, N. A., Bédirian, V., Charbonneau, S., Whitehead, V., Collin, I., et al. (2005). The Montreal Cognitive Assessment, MoCA: A Brief Screening Tool For Mild Cognitive 
Impairment. Journal of the American Geriatrics Society, 53(4), 695-699, doi:10.1111/j.15325415.2005.53221.x.

44. Karunaratne, S., Hanwella, R., \& de Silva, V. (2011). Validation of the Sinhala version of the Montreal Cognitive Assessment in screening for dementia. Ceylon Medical Journal, 56(4), 147-153, doi:http://doi.org/10.4038/cmj.v56i4.3892.

45. Kulathunga, M., Umayal, S., Somaratne, S., Srikanth, S., Kathriarachchi, S., \& De Silva, K. R. D. (2010). Validation of the Geriatric Depression Scale for an elderly Sri Lankan clinic population. Indian Journal of Psychiatry, 52(3), 254-256, doi:10.4103/0019-5545.70979.

46. StataCorp (2014). Stata 14 Stata Survey Data Reference Manual. College Station, TX: Stata Press.

47. Feng, Z., Lugtenberg, M., Franse, C., Fang, X., Hu, S., Jin, C., et al. (2017). Risk factors and protective factors associated with incident or increase of frailty among community-dwelling older adults: A systematic review of longitudinal studies. PLOS ONE, 12(6), e0178383, doi:10.1371/journal.pone.0178383.

48. Rajasi, R., Mathew, T., Nujum, Z., Anish, T., Ramachandran, R., \& Lawrence, T. (2016). Quality of life and sociodemographic factors associated with poor quality of life in elderly women in Thiruvananthapuram, Kerala. [Original Article]. Indian Journal of Public Health, 60(3), 210215, doi:10.4103/0019-557x.189016.

49. Vetrano, D. L., Palmer, K., Marengoni, A., Marzetti, E., Lattanzio, F., Roller-Wirnsberger, R., et al. (2018). Frailty and Multimorbidity: A Systematic Review and Meta-analysis. The Journals of Gerontology: Series A, gly110-gly110, doi:10.1093/gerona/gly110.

50. Williams, J. S., \& Egede, L. E. (2016). The Association Between Multimorbidity and Quality of Life, Health Status and Functional Disability. The American Journal of the Medical Sciences, 352(1), 45-52, doi:https://doi.org/10.1016/i.amjms.2016.03.004.

51. Saraiva, M. D., Suzuki, G. S., Lin, S. M., de Andrade, D. C., Jacob-Filho, W., \& Suemoto, C. K. (2018). Persistent pain is a risk factor for frailty: a systematic review and meta-analysis from prospective longitudinal studies. Age and Ageing, afy104-afy104, doi:10.1093/ageing/afy104.

52. Dueñas, M., Ojeda, B., Salazar, A., Mico, J. A., \& Failde, I. (2016). A review of chronic pain impact on patients, their social environment and the health care system. Journal of Pain Research, 9, 457-467, doi:10.2147/JPR.S105892.

53. Buchman, A. S., Boyle, P. A., Wilson, R. S., Tang, Y., \& Bennett, D. A. (2007). Frailty is Associated With Incident Alzheimer's Disease and Cognitive Decline in the Elderly. Psychosomatic Medicine, 69(5).

54. Pan, C.-W., Wang, X., Ma, Q., Sun, H.-P., Xu, Y., \& Wang, P. (2015). Cognitive dysfunction and health-related quality of life among older Chinese. Scientific Reports, 5, 17301, doi:10.1038/srep17301.

55. Liljas, A. E. M., Carvalho, L. A., Papachristou, E., Oliveira, C. D., Wannamethee, S. G., Ramsay, S. E., et al. (2017). Self-Reported Hearing Impairment and Incident Frailty in English Community-Dwelling Older Adults: A 4-Year Follow-Up Study. Journal of the American Geriatrics Society, 65(5), 958-965, doi:10.1111/jgs.14687.

56. S Dalton, D., J Cruickshanks, K., E K Klein, B., Klein, R., Wiley, T., \& M Nondahl, D. (2003). The Impact of Hearing Loss on Quality of Life in Older Adults (Vol. 43).

57. Liljas, A. E. M., Carvalho, L. A., Papachristou, E., De Oliveira, C., Wannamethee, S. G., Ramsay, S. E., et al. (2017). Self-reported vision impairment and incident prefrailty and frailty in English community-dwelling older adults: findings from a 4-year follow-up study. [10.1136/jech2017-209207]. Journal of epidemiology and community health, 71(11), 1053.

58. Brown, R. L., \& Barrett, A. E. (2011). Visual Impairment and Quality of Life Among Older Adults: An Examination of Explanations for the Relationship. The Journals of Gerontology: Series $B$, 66B(3), 364-373, doi:10.1093/geronb/gbr015.

59. Theou, O., Cann, L., Blodgett, J., Wallace, L. M. K., Brothers, T. D., \& Rockwood, K. (2015). Modifications to the frailty phenotype criteria: Systematic review of the current literature 
and investigation of 262 frailty phenotypes in the Survey of Health, Ageing, and Retirement in Europe. Ageing Research Reviews, 21, 78-94,

doi:http://dx.doi.org/10.1016/j.arr.2015.04.001.

60. Tavakol, M., \& Dennick, R. (2011). Making sense of Cronbach's alpha. International journal of medical education, 2, 53-55, doi:10.5116/ijme.4dfb.8dfd. 